\title{
Hormonal Therapies: Progesterone
}

\author{
Andrew G. Herzog \\ Harvard Neuroendocrine Unit, Beth Israel Deaconess Medical Center, Wellesley, Massachusetts 02481
}

\begin{abstract}
Summary: Seizures do not occur randomly in the majority of people with epilepsy. They tend to cluster. Seizure clusters, in turn, commonly occur with a temporal rhythmicity that shows a readily identifiable and predictable periodicity. When the periodicity of seizure exacerbation in women conforms to that of the menstrual cycle, it is commonly known as catamenial epilepsy. This may be attributable to 1 ) the neuroactive prop-
\end{abstract}

erties of steroid hormones and 2) the cyclic variation in their serum levels. If hormones play a role in seizure occurrence, hormones may also have a role in treatment. Progesterone has potent GABAergic metabolites that may provide safe and effective seizure control in women who have catamenial epilepsy. Key Words: Progesterone, epilepsy, catamenial, reproductive, hormones.

\section{INTRODUCTION}

There are reasons to consider a role for hormones in the pathophysiology and treatment of epilepsy. Reproductive steroids have neuroactive properties that can modulate neuronal excitability. Cyclic variation in the serum concentrations of neuroactive steroids are associated with and may cause a variation in seizure occurrence during the menstrual cycle that is known as catamenial epilepsy. If hormones have a role in seizure occurrence, hormones may also have a role in treatment. By way of specific therapeutic consideration and application, progesterone is a reproductive steroid that has potent neuroactive GABAergic metabolites which show antiseizure effects in experimental animal models and may have utility in the management of seizures in women with catamenial epilepsy.

\section{NEUROACTIVE PROPERTIES OF REPRODUCTIVE STEROIDS}

There is considerable scientific evidence at the molecular biological, neuronal, experimental animal, and clinical levels of investigation to suggest that some reproductive steroids have neuroactive properties that may play an important role in the pathophysiology of epilepsy and patterns of seizure occurrence (FIG. 1). Steroids act

Address correspondence and reprint requests to: Andrew G. Herzog, M.D., M.Sc., Director, Harvard Neuroendocrine Unit, Beth Israel Deaconess Medical Center, 422 Worcester Street, Suite 303, Wellesley MA 02481. E-mail: aherzog@bidmc.harvard.edu. in the brain by short-latency, direct membrane-mediated effects, ${ }^{1}$ as well as by long-latency, receptor-mediated, genomically transcribed and translated effects. ${ }^{2}$

\section{Estradiol}

Estradiol has complex, age- and sex-specific, doseand time-dependent effects on neuronal and synaptic transmission that can modulate neuronal excitability and seizures. ${ }^{3}$ Simplistically and with due deference to some differing findings, ${ }^{3}$ the prevailing view is that estradiol exerts direct excitatory effects at the neuronal membrane, where it augments NMDA-mediated excitatory neurotransmission. ${ }^{4,5}$ This enhances the resting discharge rates of neurons in a number of brain areas, including the hippocampus, ${ }^{4-6}$ where estradiol increases excitability of the hippocampal CA1 pyramidal neurons and induces repetitive firing in response to Schaffer collateral stimulation. $^{5}$

Estradiol potentiates neuronal excitability by regulating neuronal plasticity. It increases the density of spines and excitatory, NMDA receptor-containing synapses on apical dendrite branches of hippocampal CA1 pyramidal neurons via a post-transcriptional mechanism. ${ }^{7,8}$ The dendritic spine density on these neurons correlates positively with the levels of circulating estradiol during the estrous cycle of the rat and is decreased by oophorectomy. ${ }^{7,8}$ Over the course of 48 hours, however, estradiol restores inhibitory tone by increasing the density of GABA receptors. ${ }^{9}$ The combination of enhanced sensitivity to excitatory input and the restoration of inhibitory input could result in a broader dynamic range of neuronal activity. ${ }^{9}$ The com- 


\section{Contrasting Reproductive Steroid Effects in the CNS: Summary of Preclinical Evidence}

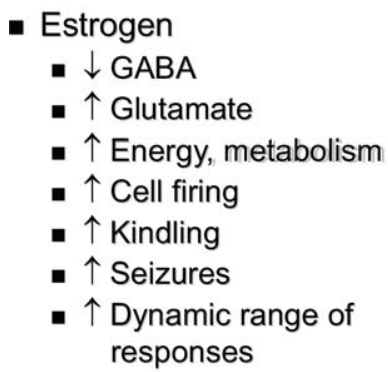

FIG. 1. Estradiol and progesterone have some contrasting effects on neuronal function.

bination of increased excitatory input and heightened firing threshold could increase synchrony of discharges, which is thought to be an important pathophysiologic mechanisms in the generation of seizures.

Estradiol may affect neuronal excitability by cytosolic neuronal estrogen receptor-mediated, genomically dependent mechanisms. ${ }^{2}$ Receptors are particularly abundant in the temporolimbic system, and especially in the medial and cortical amygdaloid nuclei; they occur in much fewer numbers in the hippocampal pyramidal cell layer and the subiculum. ${ }^{10,11}$ Estrogen receptor-containing neurons colocalize with other neurotransmitters, including GABA. ${ }^{12,13}$ By regulating the expression of genes affecting the activity, release, and postsynaptic action of different neurotransmitters and neuromodulators, estrogens may act to modulate the excitability of neurons which concentrate estradiol. For instance, estradiol can lessen inhibitory neurotransmission by decreasing GABA synthesis in the corticomedial amygdala by reducing the activity of glutamic acid decarboxylase, ${ }^{14}$ and can enhance brain epileptogenic muscarinic neurotransmission by increasing choline acetyl transferase and acetylcholine. ${ }^{15}$

In adult experimental animals, the thresholds of limbic seizures in female rats fluctuate during the estrus cycle inversely to serum estradiol levels. ${ }^{16}$ Physiological doses of estradiol activate spike discharges ${ }^{5,6,17,18}$ and lower the thresholds of seizures induced by electroshock, kindling, pentylenetetrazol, kainic acid, ethyl chloride, and other agents and procedures. ${ }^{17-22}$ In rabbits, topical brain application, as well as intravenous systemic administration, of estradiol produces a significant increase in spontaneous electrically recorded paroxysmal spike discharges. ${ }^{18}$ The increase is seen within a few seconds of application, which suggests a direct membrane rather than a genomic effect, and the increase is more dramatic in animals with pre-existent cortical lesions. ${ }^{17,18}$ The role of estrogen may be more complex, however; there is also evidence in some models that estradiol can raise seizure thresholds

in the hippocampal region and provide neuroprotection against seizure-induced injury. ${ }^{3}$

In a clinical setting, Logothetis et al. ${ }^{23}$ showed that intravenously administered conjugated estrogen clearly activated epileptiform discharges in 11 of 16 women and was associated with clinical seizures in 4 of them. Postmenopausal hormonal supplement using conjugated estrogen and medroxyprogesterone has resulted in a doserelated increase in seizure frequency as well. ${ }^{24}$

\section{Progesterone}

Progesterone, and particularly some of its neuroactive metabolites, most notably allopregnanolone (AP), exerts direct membrane-mediated inhibitory effects by potentiating $\mathrm{GABA}_{\mathrm{A}}$-mediated chloride conductance. ${ }^{1,25,26}$ Most of the membrane effect of progesterone is due to the action of AP, the $3 \alpha$-hydroxylated (i.e., A-ring-reduced) metabolite, $3 \alpha$-hydroxy-5 $\alpha$-pregnane-20-one. ${ }^{1,26}$ Both AP and the 3,5-hydroxylated natural metabolite of the mineralocorticoid deoxycorticosterone, allotetrahydrodeoxycorticosterone (alloTHDOC), are among the most potent of a number of endogenous neuroactive steroids with a direct membrane effect on neuronal excitability. ${ }^{1,25,26}$

Allopregnanolone, but not allo-THDOC, is devoid of hormonal effects and may, together with other related neuroactive steroids, be thought of as an endogenous regulator of brain excitability with anxiolytic, sedative and hypnotic, and anticonvulsant properties. ${ }^{1,25,26}$ Both $\mathrm{AP}$ and allo-THDOC hyperpolarize hippocampal and other neurons by potentiating $\mathrm{GABA}_{\mathrm{A}}$-mediated inhibition. ${ }^{1,26}$ At physiological (nanomolar) levels they interact with an extrasynaptic steroid-specific site near the synaptic receptor to facilitate chloride channel opening and prolong the inhibitory action of GABA on neurons. ${ }^{1,25,26,22-28}$ At higher pharmacological (micromolar) concentrations, AP also has a direct effect at the synaptic $\mathrm{GABA}_{\mathrm{A}}$ receptor to induce chloride currents. ${ }^{1,26}$

Allopregnanolone is one of the most potent ligands of $\mathrm{GABA}_{\mathrm{A}}$ receptors in the CNS, with affinities similar to those of the potent benzodiazepine flunitrazepam and approximately a thousand times higher than those of pentobarbital. ${ }^{1,25}$ The parent steroid, progesterone, enhances GABA-induced chloride currents only weakly and only in high concentrations. ${ }^{1,28}$ Plasma and brain levels of AP parallel those of progesterone in rats. In women, plasma levels of AP correlate with progesterone levels during the menstrual cycle and in pregnancy. ${ }^{1}$ Brain activity of progesterone and AP is not dependent solely on ovarian and adrenal production, however, because both progesterone and AP are synthesized de novo in the brain. ${ }^{29}$ Their synthesis is region specific and includes the cortex and the hippocampus. ${ }^{29}$ By contrast, allo-THDOC is synthesized only by the adrenal gland and not in the brain. ${ }^{1}$ 
Allopregnanolone, allo-THDOC, and a number of other endogenous and synthetic pregnane steroids have a potent anticonvulsant effect in bicuculline-, metrazol-, picrotoxin-, pentylenetetrazol-, pilocarpine-, and kainic acid-induced seizures and against status epilepticus, but are ineffective against electroshock- and strychnine-induced seizures. ${ }^{25,30-33}$ Allopregnanolone is an effective anticonvulsant against the secondarily generalized component of the seizure, but not against the amygdala focal discharge. ${ }^{34}$ The antiseizure effect of progesterone in progesterone receptor knockout (PRKO) mice is blocked by the reductase inhibitor finasteride, which blocks the conversion of progesterone to AP. ${ }^{35}$ The anticonvulsant properties of AP resemble those of the benzodiazepine, clonazepam. ${ }^{13,25,32}$ Although AP is less potent than clonazepam, it may have lower relative toxicity. ${ }^{31,32}$

The anticonvulsant effect of AP is greater in female rats in the diestrus 1 part of the ovulatory cycle (equivalent to human mid-luteal phase, when progesterone levels are high) than in estrus (equivalent to ovulation, when estrogen levels are high) or in the male. ${ }^{27}$ Enhanced mid-luteal efficacy at the $\mathrm{GABA}_{\mathrm{A}}$ receptor may be related to a progesterone-induced enhanced formation of the $\delta \mathrm{GABA}_{\mathrm{A}}$ receptor subtype. ${ }^{36}$ Rapid withdrawal of progesterone in late diestrus makes the GABAA receptor insensitive to benzodiazepine, but not AP, perhaps as the result of a decrease in the benzodiazepine sensitive synaptic GABAA receptors. ${ }^{32}$ This effect can be blocked by inhibiting the formation of the $\alpha 4$ subunit of the GABAA receptor. $^{32,27}$

By contrast, some of the sulfated neuroactive steroids have excitatory neuronal effects. They include pregnenolone sulfate and dehydroepiandrosterone sulfate (DHEAS), which is the naturally occurring sulfated esters of the progesterone precursor pregnenolone and progesterone metabolite DHEA. ${ }^{1}$ They increase neuronal firing when directly applied to neurons by negatively modulating the $\mathrm{GABA}_{\mathrm{A}}$ receptor ${ }^{1}$ and by facilitating glutamate-induced excitation at the NMDA receptor. ${ }^{37}$ In animal seizure models, pregnenolone sulfate and DHEAS have proconvulsant effect. ${ }^{38}$ Of note, serum DHEAS levels are substantially reduced by enzyme-inducing antiepileptic drugs such as phenytoin and carbamazepine. $^{39,40}$

Progesterone also potentiates the action of the powerful endogenous inhibitory substance adenosine. ${ }^{41}$ Progesterone itself also substantially diminishes nicotinic acetylcholine receptor-mediated conductance, which may be relevant to autosomal dominant nocturnal frontal lobe epilepsy. ${ }^{42}$

Progesterone may act via genomic mechanisms to influence the enzymatic activity controlling the synthesis and release of various neurotransmitters and neuromodulators produced by progesterone receptor-containing neurons. ${ }^{12}$ Progesterone binds specific cytosolic recep- tors not only to produce its own characteristic reproductive effects, but also to lower estrogen receptor numbers and thereby antagonize estrogen actions. ${ }^{43}$

Chronic progesterone decreases the number of hippocampal CA1 dendritic spines and excitatory synapses faster than the simple withdrawal of estrogen, counteracting the stimulatory effects of estradiol. ${ }^{8}$ Progesterone and AP have also been shown to have neuroprotective effects on hippocampal neurons in kainic acid-induced seizure models. ${ }^{44}$

In most adult female animal models, progesterone depresses neuronal firing, ${ }^{45}$ lessens spontaneous and induced epileptiform discharges, ${ }^{20-22,44-46}$ and retards kindling and decreases seizure occurrence. ${ }^{20-22,44-46}$ Hoffman et al. ${ }^{47}$ concluded that their findings in rat models are consistent with the hypothesis that progesterone produces its effects by reducing seizures, whereas estrogen has little beneficial effect on seizure behavior but protects the hippocampus from the damage that seizures produce.

Bäckström et al. ${ }^{48}$ found that intravenous infusion of progesterone sufficient to produce luteal phase serum levels was associated with a significant decrease in interictal spike frequency in four of seven women with partial epilepsy. (For results of clinical treatment trials using progestogens, see below.)

\section{DEFINITION, PATTERNS AND PREVALENCE}

Seizures do not occur randomly in the majority of men and women with epilepsy. ${ }^{49,50}$ In more than $50 \%$ of cases, they tend to cluster. ${ }^{49,50}$ Seizure clusters, in turn, may occur with temporal rhythmicity in a significant proportion of men (29\%) and women (35\%) with epilepsy (FIG. 2). ${ }^{3,51-54}$ When the periodicity of seizure exacerbation aligns with the menstrual cycle, it is commonly known as catamenial epilepsy. ${ }^{52}$ This may be attributable to 1 ) the neuroactive properties of steroid hormones and 2) the cyclic variation in their serum levels. $^{52}$

Physiological endocrine secretion during the menstrual cycle influences the occurrence of seizures (FIG. 2). In ovulatory cycles, seizure frequency shows a statistically significant positive correlation with the serum estradiol/ progesterone ratio. ${ }^{55}$ This ratio is highest during the days prior to ovulation and menstruation and is lowest during the early and mid-luteal phase. ${ }^{55}$ The premenstrual exacerbation of seizures has been attributed to the rapid withdrawal of the antiseizure effects of progesterone. ${ }^{54,55}$ Mid-cycle exacerbations may be due to the preovulatory surge of estrogen, unaccompanied by any rise in progesterone until ovulation occurs. ${ }^{54-56}$ Seizures are least common during the mid-luteal phase when progesterone levels are highest, ${ }^{54-56}$ except in anovulatory cycles, in which case the mid-cycle surge in estrogen still occurs (albeit not as high as in ovulatory cycles) but is 
not accompanied by any substantial increase in progesterone levels. ${ }^{52}$

Herzog et al. ${ }^{52,53}$ presented statistical evidence to support the concept of catamenial epilepsy and the existence of at least three distinct patterns of seizure exacerbation in relation to the menstrual cycle (FIG. 1): 1) perimenstrual (C1: day -3 to 3 ) and 2) periovulatory (C2: day 10 to -13 ) in ovulatory cycles, and 3) luteal (C3: day 10 to 3 ) in anovulatory or inadequate luteal phase cycles. In these cycles, day 1 is the first day of menstrual flow and ovulation is presumed to occur 14 days before the subsequent onset of menses (day -14). These three patterns can be demonstrated simply by first charting menses and seizures and then obtaining a midluteal phase serum progesterone level to distinguish between normal and inadequate luteal phase cycles $(<5 \mathrm{ng} / \mathrm{mL})$. One subsequent investigation has suggested that the $\mathrm{C} 1$ and $\mathrm{C} 2$ catamenial patterns show high sensitivity and specificity

\section{PATTERNS OF CATAMENIAL EPILEPSY}

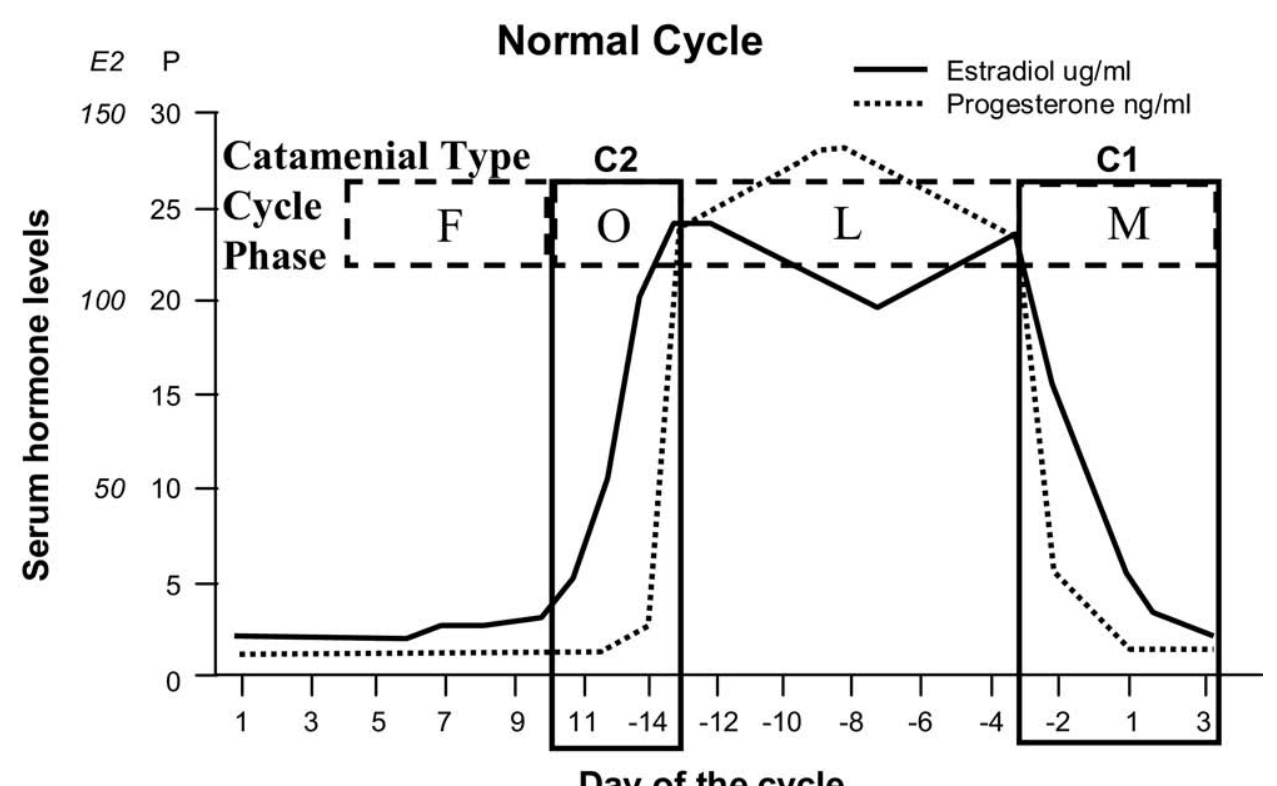

Day of the cycle

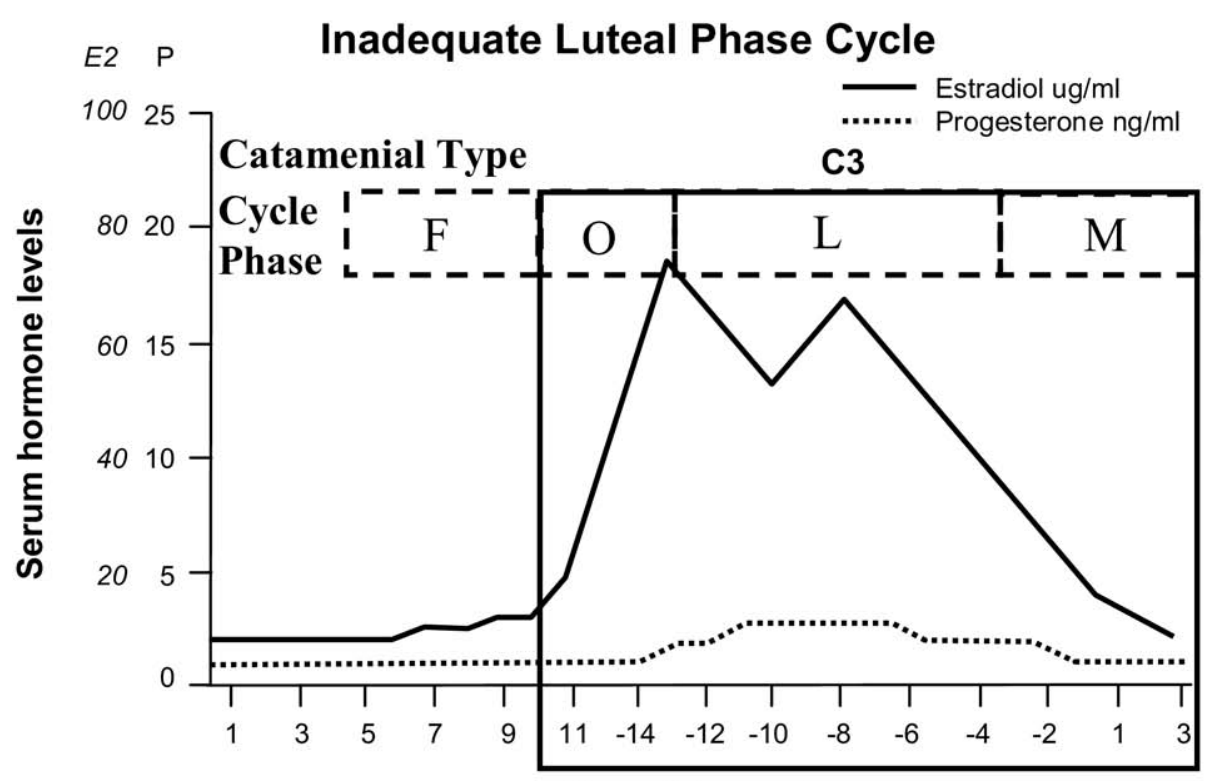

Day of the cycle

FIG. 2. Three patterns of catamenial epilepsy: perimenstrual (C1) and periovulatory (C2) exacerbations during normal ovulatory cycles and entire second half of the cycle (C3) exacerbation during inadequate luteal phase cycles, where day 1 is the first day of menstrual flow and day -14 is the day of ovulation. $\mathrm{E} 2$ = estradiol, $\mu \mathrm{g} / \mathrm{mL} ; \mathrm{F}=$ follicular phase; $\mathrm{O}=$ ovulatory phase; $\mathrm{L}=$ luteal phase; $\mathrm{M}=$ menstrual phase; $\mathrm{P}=$ progesterone, $\mathrm{ng} / \mathrm{mL}$. 
Table 1. Investigational Sex Hormone Treatments for Women with Epilepsy

\begin{tabular}{|c|c|c|}
\hline Investigational Treatment & Dosage & Potential Adverse Effects \\
\hline Progesterone lozenges & $\begin{array}{l}0.5-1 \text { lozenge t.i.d., days } 14-25 \\
0.25-0.5 \text { lozenge t.i.d., days } 26-27 \\
0.25 \text { lozenge t.i.d., day } 28\end{array}$ & $\begin{array}{l}\text { Sedation, depression, breast } \\
\text { tenderness, vaginal bleeding, } \\
\text { constipation, exacerbation of } \\
\text { asthma, weight gain }\end{array}$ \\
\hline Depomedroxyprogesterone & 150-250 mg i.m. q 1-3 months & $\begin{array}{l}\text { As above, plus delay of months to } \\
2 \text { years in recovery of ovulatory } \\
\text { cycles during which time seizure } \\
\text { numbers may increase sometimes } \\
\text { beyond baseline }\end{array}$ \\
\hline GnRH analog: leuprolide & $3.75 \mathrm{mg}$ i.m. q 4 weeks; $11.25 \mathrm{mg}$ i.m. q 12 weeks & $\begin{array}{l}\text { Menopausal symptoms unless } \\
\text { concomitant estradiol and } \\
\text { progesterone supplement is } \\
\text { administered }\end{array}$ \\
\hline Clomiphene & $25-50 \mathrm{mg}$ daily, days $5-9$ & Ovarian overstimulation syndrome* \\
\hline
\end{tabular}

$\mathrm{GnRH}=$ gonadotrophin-releasing hormone.

*Distention of ovaries can be very painful.

for occurrence in ovulatory cycles, whereas the $\mathrm{C} 3$ pattern shows high sensitivity but only moderate specificity for occurrence during anovulatory cycles, occurring also in ovulatory cycles in which the mid-luteal estradiol/ progesterone ratio was high. ${ }^{57}$

Although the precise definition of catamenial epilepsy remains arbitrary, one may maximize the efficiency of distinguishing between women whose seizure occurrence shows a high versus a low degree of hormonal sensitivity by using the points of inflection of the Sshaped distribution curves that define the relationship between the severity of seizure exacerbation and the number of women who have exacerbation. ${ }^{52,53}$ These points are calculated to be in the vicinity of a twofold increase in average daily seizure frequency during the phases of exacerbation, relative to the baseline phases, for all three types of catamenial exacerbation. We propose the use of these points of inflection values in seizure frequency for the designation of catamenial epilepsy. By this criterion, approximately one third of women with intractable partial epilepsy would qualify for the designation of having catamenial epilepsy. ${ }^{52,53}$ Adoption of a standard (albeit arbitrary) nomenclature may provide greater uniformity in study designs for the investigation of the pathogenesis and treatment of catamenial seizure exacerbation.

\section{HORMONAL TREATMENT}

\section{Progestogen therapy}

The term progestogen refers to the broad class of progestational agents. These include progesterone (i.e., naturally occurring progesterone) and progestins (i.e., synthetic progestational agents). Progestogen treatment (Tables 1 and 2) has taken two forms: 1) cyclic progesterone therapy that supplements progesterone during the luteal phase and withdraws it gradually premenstrually and 2) suppressive therapy, in which the goal is to suppress the menstrual cycle (generally accomplished using

Table 2. Adjunctive Cyclic Progestogen Therapy

\begin{tabular}{|c|c|c|c|c|}
\hline & Medroxyprogesterone & $\begin{array}{l}\text { Progesterone } \\
\text { Suppositories }\end{array}$ & Progesterone Lozenges & Progesterone Lozenges \\
\hline Regimen & $\begin{array}{l}5-10 \mathrm{mg} \text {. q.d., days } \\
15-28 \text { of cycle }\end{array}$ & $\begin{array}{l}100-200 \mathrm{mg} \text {. t.i.d., days } \\
15-28 \text { of cycle }\end{array}$ & $\begin{array}{l}100-200 \text { mg. t.i.d., days } \\
15-28 \text { of cycle }\end{array}$ & $\begin{array}{l}100-200 \mathrm{mg} \text {. t.i.d., days } \\
15-28 \text { of cycle }\end{array}$ \\
\hline $\begin{array}{l}\text { Follow-up } \\
\text { assessment }\end{array}$ & 3 months & 3 months & 3 months & 3 years \\
\hline Subjects, no. & 24 & 8 & 25 & $15^{*}$ \\
\hline Improved, no. (\%) & $10(42)$ & $6(75 \%)$ & $18(72 \%)$ & $15(100)^{*}$ \\
\hline $\begin{array}{l}\text { Seizure frequency, } \\
\% \text { change }\end{array}$ & -10 & $-68^{\dagger}$ & $\begin{array}{l}-54^{\ddagger} \mathrm{CPS} ;-58^{\dagger} \\
\text { SGMS }\end{array}$ & $\begin{array}{l}-62^{\ddagger} \text { CPS; }-74^{\ddagger} \\
\text { SGMS }\end{array}$ \\
\hline
\end{tabular}

CPS $=$ complex partial seizure; SGMS $=$ secondary generalized motor seizures .

*The 15 subjects with a 3-year assessment, reported by Herzog ${ }^{62}$ in 1999 , are a subset of the 25 subjects reported by Herzog ${ }^{61}$ in 1995 . All 15 of these subjects $(100 \%)$ showed improvement at 3 years, ${ }^{62}$ which represents $60 \%$ of the original subjects. ${ }^{61}$

${ }^{\dagger} p<0.05$.

${ }^{\ddagger} p<0.01$. 
injectable progestins or long-acting, gonadotropin releasing-hormone analogs) (Table 1).

\section{Cyclic progesterone therapy}

In contrast to published reports of cyclic oral progestin investigations that have not been shown to have efficacy in producing significant reductions in seizure frequency, ${ }^{58,59}$ two open-label trials of adjunctive progesterone therapy for women with catamenial epilepsy have documented substantial and statistically significant reductions in seizure occurrence (Table 2). ${ }^{60,61}$ In one investigation of women who had inadequate luteal phase cycles with catamenial exacerbation of intractable complex partial seizures, 6 of 8 women experienced improved seizure control, with a $68 \%$ decline in average monthly seizure frequency over 3 months for the whole group. ${ }^{60}$ In a subsequent openlabel trial of adjunctive cyclic progesterone versus the optimal antiseizure medication alone in 25 women with perimenstrual catamenial seizure exacerbation (14 with anovulatory cycles and 11 with ovulatory cycles), 18 of the women $(72 \%)$ experienced fewer seizures, with an overall average monthly decline of $54 \%$ for complex partial and 58\% for secondary generalized seizures over 3 months. ${ }^{61}$ Progesterone was more efficacious when administered during the entire second half of the cycle, rather than just premenstrually, and then tapered and discontinued gradually over 3 or 4 days at the end of the cycle. ${ }^{61}$ Failure to taper gradually premenstrually can result in rebound seizure exacerbation.

At 3 years, 15 of the 18 women who had fewer seizures remained on both cyclic progesterone therapy and their original antiepileptic drugs continued to show improved seizure control, compared with their own baseline (Table 2). ${ }^{62}$ Three women were entirely seizure free, four had total seizure reductions of $75 \%$ to $99 \%$, and eight had reductions of $50 \%$ to $74 \%$. Complex partial seizures in these 15 women were lower by a statistically significant $62 \%$; secondary generalized motor seizures were reduced by a statistically significant $74 \%$. Antiepileptic drug serum levels did not show any significant change between treatment and baseline values. The three remaining women who continued on progesterone therapy had $10 \%$ to $50 \%$ improvement at the end of the original investigation at 3 months; they were not considered further for this analysis because they changed antiepileptic drugs.

By way of critique, the weakness of these preliminary progesterone investigations is that they were not placebocontrolled or blinded. The favorable 3-year follow-up results are biased by analysis of only 15 of the original 25 subjects. These 15 who remained on the original treatment regimen are more likely to represent those who had the most favorable response. Nonetheless, there are reasons why the results of the present investigation may represent more than placebo effects. First, few placebo studies (including our own oral synthetic progestin trial that used a similar methodology, and could be used, therefore, as a retrospective control), show favorable response in more than $50 \%$ of subjects. Second, few placebo treatments have resulted in greater than $50 \%$ seizure reduction. Third, although placebo effects generally wear off over a few months, substantial and statistically significant improvements in the present investigation persisted after 3 years in the majority of subjects. ${ }^{62}$

Another argument against the placebo explanation is that the beneficial effect of progesterone can be eliminated by the concomitant use of a reductase inhibitor, which presumably blocks the reduction of progesterone to its potent GABAergic metabolite AP. ${ }^{63}$ Finally, there is transcranial magnetic stimulation evidence that progesterone may increase inhibition in the brain premenstrually. ${ }^{64}$ A prospective multicenter, randomized, double-blind, placebo-controlled investigation of cyclic, adjunctive progesterone therapy in the management of women with catamenially exacerbated, intractable localization related epilepsy is now under way. ${ }^{50,53,57}$

Natural progesterone is available as an extract of soy or yams in lozenge form in various dosages ranging from $25 \mathrm{mg}$ to $200 \mathrm{mg}$. and should be administered three times daily because of its brief half-life of approximately 4 to 6 hours. ${ }^{60-62}$ The daily regimen to achieve physiological luteal range serum levels measured 4 hours after administration ranges from $50 \mathrm{mg}$ to $200 \mathrm{mg}$, taken three times daily, with the usual optimal daily dose ranging from 300 $\mathrm{mg}$ to $600 \mathrm{mg} .{ }^{60-62}$ The maintenance dosage and regimen should be individualized, based on a combination of clinical response and serum progesterone levels between 20 and $40 \mathrm{ng} / \mathrm{mL}$. Progesterone is also available in micronized form in an oral caplet preparation that may also exert similar antiseizure effects, although formal investigations to this effect are lacking. Theoretically, it is possible that first pass through the liver using the oral micronized form may result in the delivery of different concentrations of progesterone and its neuroactive metabolite to the brain.

The most common adverse effects include sedation, emotional depression, and asthenia. ${ }^{60-62}$ Progesterone use may also occasionally be associated with breast tenderness, weight gain, and irregular vaginal bleeding, and sometimes constipation. Discontinuation of the hormone or lowering of the dosage resolves these adverse effects. ${ }^{60-62}$

Drug interactions are an important consideration. Higher progesterone dosages may be required to achieve luteal range levels in women who take antiseizure medications because carbamazepine, phenytoin, and barbiturates are known to enhance the hepatic metabolism of gonadal and adrenal steroid hormones as well as to increase hormonal binding to serum proteins. ${ }^{63}$ Progesterone use has been associated with changes in antiseizure 
medication levels in some cases, but this effect has been sporadic and has not occurred in a predictable direction. It may be advisable, therefore, to check serum antiseizure medication levels during the initiation of concomitant hormonal therapy.

\section{Progestin therapy}

Parenteral depomedroxyprogesterone may lower seizure frequency when it is given in sufficient dosage to induce amenorrhea. ${ }^{59,65}$ In one open-label study of 14 women with refractory partial seizures and normal ovulatory cycles, parenteral depomedroxyprogesterone administration in doses large enough to induce amenorrhea (i.e., 120-150 mg every 6-12 weeks) resulted in a 39\% seizure reduction. ${ }^{59}$ It was unclear whether the effect was due to direct anticonvulsant activity of medroxyprogesterone or to the hormonal consequences of the induced amenorrhea. One patient, who had absence rather than partial seizures, did not improve. Adverse effects included those encountered with natural progesterone. Depot administration, however, is also commonly associated with hot flashes, irregular breakthrough vaginal bleeding, and a lengthy delay of 6 to 12 months in the return of regular ovulatory cycles. ${ }^{59}$ Long-term hypoestrogenic effects on cardiovascular and emotional status, as well as headache, need to be considered with chronic use. Bone density is only partially maintained.

Oral synthetic progestins administered cyclically or continuously have not proven to be an effective therapy for seizures in clinical investigations, ${ }^{58,59}$ although individual successes with continuous daily oral use of norethisterone and combination pills have been reported. ${ }^{66}$

\section{Gonadotrophin-releasing hormone analog therapy}

Bauer et al. ${ }^{67}$ used triptorelin, a synthetic gonadotrophin-releasing hormone $(\mathrm{GnRH})$ analog $(3.75 \mathrm{mg})$ in a controlled-release depot form intramuscularly every 4 weeks for an average of 11.8 months in 10 women (aged 20-50) with catamenial seizures intractable to high therapeutic doses of carbamazepine, diphenylhydantoin, phenobarbital, and valproic acid in monotherapy or combination. They remained on a stable dose of the anticonvulsant throughout the period of treatment with triptorelin. Three patients became seizure free, and four showed a decrease in seizure frequency of up to $50 \%$. In one the duration of seizures was shortened, and in two there was no therapeutic effect. These results were attained within the first 2 months of starting triptorelin. The study was not a controlled study, and longer term follow-up was not available for some of the patients. Serum luteinizing hormone and estrogen were measured in one patient before and during the 2nd month of triptorelin treatment; and as expected showed marked inhibition of luteinizing hormone and estrogen production. All 10 women became amenorrheic, and 8 of them experienced hot flashes, headache, or weight gain.
Haider and Barnett ${ }^{68}$ reported on their use of goserelin $3.6 \mathrm{mg}$ subcutaneously every 4 weeks in a 41 -year-old woman who had had frequent catamenial status epilepticus despite therapeutic anticonvulsant drug levels which also did not respond to levonorgestrel-ethinyl estradiol. They reported a decrease in frequency from 10 admissions for status epilepticus to 3 over a similar period.

The GnRH analogs basically create a medical oophorectomy. Common adverse effects are flushing, vaginal dryness, and dyspareunia. Serious long-term risks include osteoporosis and cardiovascular disease. Reid and Gangar ${ }^{69}$ suggested the addition of medroxyprogesterone acetate and conjugated estrogens to goserelin to prevent this while still abolishing most of the cyclical fluctuations of ovarian hormones. Finkelstein et al. ${ }^{70}$ recently discussed the use of parathyroid hormone to prevent bone loss in women treated with GnRH analogs. Although neither Bauer et al. ${ }^{67}$ nor Haider and Barnett ${ }^{68}$ reported exacerbation of seizures with GnRH analogs, we have found that during the first 3 weeks, when there is an initial stimulation of ovarian estradiol production before it is inhibited, women may experience a marked exacerbation of their seizures. ${ }^{36,71}$

\section{REFERENCES}

1. Paul SM, Purdy RH. Neuroactive steroids. FASEB J 1992;6:23112322.

2. McEwen BS. How do sex and stress hormones affect nerve cells? Ann NY Acad Sci 1994;743:1-16.

3. Velî́sová J, Velíšek L, Galanopoulou AS, Sperber EF. Neuroprotective effects of estrogens on hippocampal cells in adult female rats after status epilepticus. Epilepsia 2000;41 Suppl 6:S30-S35.

4. Smith SS. Estrogen administration increases neuronal responses to excitatory amino acids as a long-term effect. Brain Res 1989;503: 354-357.

5. Wong M, Moss R. Long-term and short-term electrophysiological effects of estrogen on the synaptic properties of hippocampal CA1 neurons. J Neurosci 1992;12:3217-3225.

6. Kawakami M, Terasawa E, Ibuki T. Changes in multiple unit activity in the brain during the estrous cycle. Neuroendocrinology 1970;6:30-48.

7. Woolley CS, McEwen BS. Roles of estradiol and progesterone in regulation of hippocampal dendritic spine density during the estrous cycle in the rat. J Comp Neurol 1993;336:293-306.

8. Woolley CS, McEwen BS. Estradiol regulates hippocampal dendritic spine density via an $N$-methyl-D-aspartate receptor-dependent mechanism. J Neurosci 1994;14:7680-7687.

9. Rudick CN, Woolley CS. Estrogen regulates functional inhibition of hippocampal CA1 pyramidal cells in the adult female rat. J Neurosci 2001;21:6532-6543.

10. Pfaff DW, Keiner M. Estradiol-concentrating cells in the rat amygdala as part of a limbic-hypothalamic hormone-sensitive system. In: Eleftheriou BE, The neurobiology of the amygdala. New York: Plenum Press, 1973:775-792.

11. Simerly RB, Chang C, Muramatsu M, Swanson LW. Distribution of androgen and estrogen receptor mRNA-containing cells in the rat brain: an in situ hybridization study. J Comp Neurol 1990;294: $76-95$.

12. McEwen BS. Non-genomic and genomic effects of steroids on neural activity. Trends Pharmacol Sci 1991;12:141-147.

13. Finn DA, Gee KW. The influence of estrus cycle on neurosteroid potency at the gamma-aminobutyric $\operatorname{acid}_{\mathrm{A}}$ receptor complex. J Pharmacol Exp Ther 1993;265:1374-1379. 
14. Wallis CJ, Luttge WG. Influence of estrogen and progesterone on glutamic acid decarboxylase activity in discrete regions of rat brain. J Neurochem 1980;34:609-613.

15. Luine VN, Renner KJ, McEwen BS. Sex-dependent differences in estrogen regulation of choline acetyltransferase are altered by neonatal treatments. Endocrinology 1986;119:874-878.

16. Terasawa E, Timiras P. Electrical activity during the estrous cycle of the rat: cyclic changes in limbic structures. Endocrinology 1968; 83:207-216.

17. Logothetis J, Harner R. Electrocortical activation by estrogens. Arch Neurol 1960;3:290-297.

18. Marcus EM, Watson CW, Goldman PL. Effects of steroids on cerebral electrical activity. Arch Neurol 1966;15:521-532.

19. Hom AC, Buterbaugh GG. Estrogen alters the acquisition of seizures kindled by repeated amygdala stimulation or pentylenetetrazol administration in ovariectomized female rats. Epilepsia 1986; 27:103-108.

20. Nicoletti F, Speciale C, Sortino MA, et al. Comparative effects of estradiol benzoate, the antiestrogen clomiphene citrate, and the progestin medroxyprogesterone acetate on kainic acid-induced seizures in male and female rats. Epilepsia 1985;26:252-257.

21. Spiegel EA, Wycis HT. Anticonvulsant effects of steroids. J Lab Clin Med 1945;30:947-953.

22. Woolley DE, Timiras PS. The gonad-brain relationship: effects of female sex hormones on electroshock convulsions in the rat. Endocrinology 1962;70:196-209.

23. Logothetis J, Harner R, Morrell F, Torres F. The role of estrogens in catamenial exacerbation of epilepsy. Neurology 1959;9:352360.

24. Harden CL, Herzog AG, Nikolov BG, et al. Hormone replacement therapy in women with epilepsy: a randomized, double-blind, placebo-controlled study. Epilepsia 2006;47:1447-1451.

25. Majewska MD, Harrison NL, Schwartz RD, Barker JL, Paul SM. Steroid hormone metabolites are barbiturate-like modulators of the GABA receptor. Science 1986;232:1004-1007.

26. Gee KW, McCauley LD, Lan NC. A putative receptor for neurosteroids on the $\mathrm{GABA}_{\mathrm{A}}$ receptor complex: the pharmacological properties and therapeutic potential of epalons. Crit Rev Neurobiol 1995;9:207-227.

27. Maguire JL, Stell BM, Rafizadeh M, Mody I. Ovarian cycle-linked changes in $\mathrm{GABA}_{\mathrm{A}}$ receptors mediating tonic inhibition alter seizure susceptibility and anxiety. Nat Neurosci 2005;8:797-804.

28. Wu FS, Gibbs TT, Farb DH. Inverse modulation of $\gamma$-aminobutyric acid- and glycine-induced currents by progesterone. Mol Pharmacol 1990;37:597-602.

29. Cheney DL, Uzunov D, Costa E, Guidotti A. Gas chromatographic-mass fragmentographic quantitation of $3 \alpha$-hydroxy-5 $\alpha$-pregnan-20-one (allopregnanolone) and its precursors in blood and brain of adrenalectomized and castrated rats. J Neurosci 1995;15: 4641-4650.

30. Belelli D, Bolger MB, Gee KW. Anticonvulsant profile of the progesterone metabolite $5 \alpha$-pregnan-3 $\alpha$-ol-20-one. Eur J Pharmacol 1989;166:325-329.

31. Kokate TG, Svensson BE, Rogawski MA. Anticonvulsant activity of neurosteroids: correlation with $\gamma$-aminobutyric acid-evoked chloride current potentiation. J Pharmacol Exp Ther 1994;270: $1223-1229$.

32. Kokate TG, Cohen AL, Karp E, Rogawski MA. Neuroactive steroids protect against pilocarpine- and kainic acid-induced limbic seizures and status epilepticus in mice. Neuropharmacology 1996; 35:1049-1056.

33. Rhodes ME, Frye CA. Progestins in the hippocampus of female rats have antiseizure effects in a pentylenetetrazole seizure model. Epilepsia 2004;45:1531-1538.

34. Lonsdale D, Nylen K, McIntyre Burnham W. The anticonvulsant effects of progesterone and its metabolites on amygdala-kindled seizures in male rats. Brain Res 2006;1101:110-116.

35. Reddy DS, Castaneda DC, O'Malley BW, Rogawski MA. Anticonvulsant activity of progesterone and neurosteroids in progesterone receptor knockout mice. J Pharmacol Exp Ther 2004;310: $230-239$.

36. Smith SS, Gong QH, Hsu FC, Markowitz RS, ffrench-Mullen $\mathrm{JMH}$, Li X. GABA $\mathrm{A}$ receptor $\alpha 4$ subunit suppression prevents withdrawal properties of an endogenous steroid. Nature 1998;392:926-930.

37. Irwin RP, Maragakis NJ, Rogawski MA, Purdy RH, Farb DH, Paul SM. Pregnenolone sulfate augments NMDA receptor mediated increases in intracellular $\mathrm{Ca}^{2+}$ in cultured rat hippocampal neurons. Neurosci Lett 1992;141:30-34.

38. Heuser G, Ling GM, Buchwald NA. Sedation or seizures as dosedependent effects of steroids. Arch Neurol 1965;13:195-203.

39. Levesque LA, Herzog AG, Seibel MM. The effect of phenytoin and carbamazepine on dehydroepiandrosterone sulfate in men and women who have partial seizures with temporal lobe involvement. J Clin Endocrinol Metab 1986;63:243-245.

40. Herzog AG, Drislane FW, Schomer DL, et al. Differential effects of antiepileptic drugs on serum neuroactive steroid concentrations in men with localization-related epilepsy. Epilepsia 2006;47:19451948.

41. Phyllis JW. Potentiation of the depression by adenosine of rat cerebral cortex neurones by progestational agents. Br J Pharmacol 1986;89:693-702.

42. Valera S, Ballivet M, Bertrand D. Progesterone modulates a neuronal nicotinic acetylcholine receptor. Proc Natl Acad Sci U S A 1992;89:9949-9953.

43. Hsueh AJW, Peck EJ, Clark JH. Control of uterine estrogen receptor levels by progesterone. Endocrinol 1976;98:438-444.

44. Frye CA. The neurosteroid $3 \alpha, 5 \alpha$-THP has antiseizure and possible neuroprotective effects in an animal model of epilepsy. Brain Res 1995;696:113-120.

45. Smith SS, Waterhouse BD, Woodward DJ. Sex steroid effects on extrahypothalamic CNS: II. Progesterone, alone and in combination with estrogen, modulates cerebellar responses to amino acid neurotransmitters. Brain Res 1987;422:52-62.

46. Landgren S, Bäckström T, Kalistratov G. The effect of progesterone on the spontaneous interictal spike evoked by the application of penicillin to the cat's cerebral cortex. J Neurol Sci 1978;36: $119-133$.

47. Hoffman GE, Moore N, Fiskum G, Murphy AZ. Ovarian steroid modulation of seizure severity and hippocampal cell death after kainic acid treatment. Exp Neurol 2003;182:124-134.

48. Bäckström T, Zetterlund B, Blom S, Romano M. Effects of intravenous progesterone infusions on the epileptic discharge frequency in women with partial epilepsy. Acta Neurol Scand 1984;69:240248.

49. Taubøll E, Lundervold A, Gjerstad L. Temporal distribution of seizures in epilepsy. Epilepsy Res 1991;8:153-165.

50. Fowler K, Massaro J, Harden C, et al. Distribution of seizure occurrence in women with epilepsy: preliminary data analysis in a prospective multicenter investigation. Epilepsia 2006;47 Suppl 4:1 (abstract).

51. Almqvist R. The rhythm of epileptic attacks and its relationship to the menstrual cycle. Acta Psychiatr Neurol Scand Suppl 1955;105: $1-116$.

52. Herzog AG, Klein P, Ransil BJ. Three patterns of catamenial epilepsy. Epilepsia 1997;38:1082-1088.

53. Herzog AG, Harden CL, Liporace J, et al. Frequency of catamenial seizure exacerbation in women with localization-related epilepsy. Ann Neurol 2004;56:431-434.

54. Quigg M, Fowler KM, Herzog AG; NIH Progesterone Trial Study Group. Circalunar and ultralunar periodicities in women with partial seizures. Epilepsia 2008;49:1081-1085.

55. Bäckström T. Epileptic seizures in women related to plasma estrogen and progesterone during the menstrual cycle. Acta Neurol Scand 1976;54:321-347.

56. Laidlaw J. Catamenial epilepsy. Lancet 1956;271:1235-1237.

57. Herzog AG, Fowler KM; NIH Progesterone Trial Study Group. Sensitivity and specificity of the association between catamenial seizure patterns and ovulation. Neurology 2008;70:486-487.

58. Dana-Haeri J, Richens A. Effect of norethisterone on seizures associated with menstruation. Epilepsia 1983;24:377-381.

59. Mattson RH, Cramer JA, Caldwell BV, Siconolfi BC. Treatment of seizures with medroxyprogesterone acetate: preliminary report. Neurology 1984;34:1255-1258.

60. Herzog AG. Intermittent progesterone therapy and frequency of 
complex partial seizures in women with menstrual disorders. Neurology 1986;36:1607-1610.

61. Herzog AG. Progesterone therapy in complex partial and secondary generalized seizures. Neurology 1995;45:1660-1662.

62. Herzog AG. Progesterone therapy in women with epilepsy: a 3-year follow-up. Neurology 1999;52:1917-1918.

63. Herzog AG, Frye CA. Seizure exacerbation associated with inhibition of progesterone metabolism. Ann Neurol 2003;53:390-391.

64. Herzog AG, Friedman MN, Freund S, Pascual-Leone A. Transcranial magnetic stimulation evidence of a potential role for progesterone in the modulation of premenstrual corticocortical inhibition in a woman with catamenial seizure exacerbation. Epilepsy Behav 2001;2:367-369.

65. Zimmerman AW, Holden KR, Reiter EO, Dekaban AS. Medroxyprogesterone acetate in the treatment of seizures associated with menstruation. J Pediatr 1973;83:959-963.
66. Hall SM. Treatment of menstrual epilepsy with a progesteroneonly oral contraceptive. Epilepsia 1977;18:235-236.

67. Bauer J, Wildt L, Flügel D, Stefan H. The effect of a synthetic GnRH analogue on catamenial epilepsy: a study in ten patients. J Neurol 1992;239:284-286.

68. Haider Y, Barnett DB. Catamenial epilepsy and goserelin. Lancet 1991;338:1530

69. Reid B, Gangar KF. Catamenial epilepsy and goserelin. Lancet 1992;339:253.

70. Finkelstein JS, Klibanski A, Schaefer EH, Hornstein MD, Schiff I, Neer RM. Parathyroid hormone for the prevention of bone loss induced by estrogen deficiency. N Engl J Med 1994;331:1618 1623.

71. Herzog AG. Reproductive endocrine considerations and hormonal therapy for women with epilepsy. Epilepsia 1991;32 Suppl 6:S27S33. 